Article

\title{
Five Years (2014-2018) of Beta Activity Concentration and the Impact of Synoptic and Local Meteorological Conditions in Bilbao (Northern Spain)
}

\author{
Natalia Alegría ${ }^{1, *(\mathbb{D}}$, Miguel Ángel Hernández-Ceballos ${ }^{2}$ (), Margarita Herranz ${ }^{1}\left(\mathbb{D}\right.$, Raquel Idoeta ${ }^{1(\mathbb{D}}$ \\ and Fernando Legarda ${ }^{1}$ \\ 1 Department of Energy Engineering, University of the Basque Country, 48013 Bilbao, Spain; \\ m.herranz@ehu.eus (M.H.); raquel.idoeta@ehu.eus (R.I.); f.legarda@ehu.eus (F.L.) \\ 2 Department of Physics, University of Cordoba, 14071 Córdoba, Spain; f92hecem@uco.es \\ * Correspondence: natalia.alegria@ehu.eus; Tel.: +34-94-601-7279
}

\section{check for}

updates

Citation: Alegría, N.;

Hernández-Ceballos, M.Á.; Herranz,

M.; Idoeta, R.; Legarda, F. Five Years

(2014-2018) of Beta Activity

Concentration and the Impact of

Synoptic and Local Meteorological

Conditions in Bilbao (Northern

Spain). Atmosphere 2021, 12, 1323.

https://doi.org/10.3390/

atmos12101323

Academic Editor: Martin Gallagher

Received: 24 September 2021

Accepted: 7 October 2021

Published: 10 October 2021

Publisher's Note: MDPI stays neutral with regard to jurisdictional claims in published maps and institutional affiliations.

\begin{abstract}
The aim of this paper is to statistically characterize gross beta activity concentrations in ground-level air in Bilbao (northern Spain) by analysing five years (2014-2018) worth of weekly measurements in aerosols collected in filters to analyse the impact of local meteorological parameters on concentrations. In addition, synoptic meteorological scenarios associated with anomalous beta surface activity concentrations were identified. Over this five-year period, beta activity concentrations ranged from $35.45 \mu \mathrm{Bq} / \mathrm{m}^{3}$ to $1778 \mu \mathrm{Bq} / \mathrm{m}^{3}$ with a mean of $520.12 \pm 281.77 \mu \mathrm{Bq} / \mathrm{m}^{3}$. A positive correlation was found with the alpha concentrations (0.67), with an average of 0.138 for the alpha/beta ratio, and a low correlation was found with ${ }^{7} \mathrm{Be}(0.16)$. Statistical analysis identified a seasonal component in the time series, increasing, on average, beta activity concentrations from winter to autumn. The highest beta activity concentrations were measured under the arrival of southerly land winds with low wind speeds, while the wind analysis (surface winds and air masses) of two different seasonal periods (autumn 2015 and winter 2017) have highlighted how small variations in synoptic and local winds highly influence beta activity concentrations. These results are relevant to understand the meteorological factors affecting beta activity concentrations in this area and hence to define meteorological scenarios that are in favour to high/anomalous surface activity concentrations that are harmful to the environmental and public health.
\end{abstract}

Keywords: gross beta activity; meteorological parameters; air masses; surface winds; northern Spain

\section{Introduction}

The presence of gross beta activity concentrations in the air can be explained in normal situations as being due to the presence of long-lived daughters of gaseous ${ }^{222} \mathrm{Rn}$, such as ${ }^{210} \mathrm{~Pb}\left(\mathrm{~T}_{1 / 2}=22.2\right.$ years $)$ and ${ }^{210} \mathrm{Bi}\left(\mathrm{T}_{1 / 2}=5.01\right.$ days $)$, which are attached to aerosols after cluster formation [1-3], and the presence of cosmogenic radionuclides such as ${ }^{7} \mathrm{Be},{ }^{22} \mathrm{Na}$, and so on [3]. Therefore, the atmosphere is not free of beta emitters, the concentration of them being due to the descendants of radons such as those from the alpha emitters if it is assumed that they are in secular equilibrium in the atmosphere [4]. In addition, when a nuclear accident or incident occurs, part of the radionuclides released into the atmosphere are beta emitters (e.g., ${ }^{90} \mathrm{Sr}_{-}{ }^{90} \mathrm{Y}$, and $\left.{ }^{129} \mathrm{I}-{ }^{131} \mathrm{I}\right)$ [5], which results in the need to measure gross beta activities and the calculation of the dose received by the population to identify unusual levels of radioactivity. The possibility of having measurements of gross beta activity concentrations is as such important in order to control radioactivity levels, which are hazardous to humans when emitter nuclei are inhaled, and to establish the temporal and spatial variation of radionuclide concentrations in the atmosphere.

The environmental radioactivity levels in the atmosphere, under normal and accident conditions, are determined by meteorological conditions. Many studies have performed 
analyses on the relationship between meteorological conditions and the concentration of diverse radionuclides in the air [6,7]. The understanding of aerosol gross activity concentrations and the detection of activity peaks or anomalies in a region is then based on the evaluation, analysis, and identification of the main meteorological scenarios and parameters influencing them, such as rainfall, temperature, relative humidity, pressure, and wind speed and wind direction. In this sense, several studies have explained the variation of gross beta activities and their relationship with meteorological parameters in the Iberian Peninsula, such as Sáez-Muñoz et al., 2018, in Valencia (east) [8]; Dueñas et al., 1999, and Cabello et al., 2018, in Malaga (south) [9,10]; García-Talavera et al., 2001, in Salamanca (west) [11]; and Rodas Ceballos et al., 2016, [12] and Hernández et al., 2005, [13] in the Balearic and Canary Islands, respectively. However, and to the authors knowledge, in the north of the Iberian Peninsula, which as different meteorological and climatic conditions, there is a lack of studies analysing gross beta activity concentrations and their link with meteorological conditions. The findings of this investigation hence complement those of earlier studies, and on top of this, it provides insights on the impact of synoptic meteorological conditions on anomalous beta activity concentrations.

This paper characterizes the gross beta activity concentrations and identifies the meteorological factors influencing its temporal distribution in the city of Bilbao (Spain). We have used weekly measurements of gross beta activities spanning a five-year period (2014-2018), with the main purpose of finding variation in gross specific activities and their correlations with meteorological parameters.

\section{Materials and Methods}

\subsection{Study Area}

Airborne particulate samples were collected weekly on the roof of the Faculty of Engineering of Bilbao $\left(43.26^{\circ} \mathrm{N},-2.9^{\circ} \mathrm{W}\right)$ from January 2014 to December 2018. This period was selected to analyse the relationship between beta activity concentrations and meteorological parameters because it covers the new location of the air sampler close to the meteorological station (Figure 1b). Bilbao, located in the narrow valley of the Nervion river, is on the north coast of Spain and is about $16 \mathrm{~km}$ away from the sea and is surrounded by hills, with an altitude between 80 and $300 \mathrm{~m}$ (Figure 1a) [14,15].

Bilbao has a humid oceanic climate with a predominance of westerly winds. Due to the proximity to the sea, the climate is mild and does not have very marked thermal contrasts between seasons: $8{ }^{\circ} \mathrm{C}$ average temperature in winter and $20^{\circ} \mathrm{C}$ in summer. The average annual precipitation is over $1000 \mathrm{~mm}$.

Figure 2 shows the surface wind rose diagrams that represent the wind speeds and directions in Bilbao during the study period (2014-2018). Hourly wind speed and wind direction values recorded were used. While the length of each spoke around the circle indicates the frequency at which the wind blew from the indicated direction in the present study period, the colors indicate wind speed categories from each direction. Winds predominantly come from two main directions, northwest and south-southwest, and wind speeds are usually below $6 \mathrm{~m} / \mathrm{s}$. This figure also shows the evolution of weekly temperature averages and the relative humidity as well as the total amount of precipitation from 2014 and 2018. These measurements are used in the present analysis. 

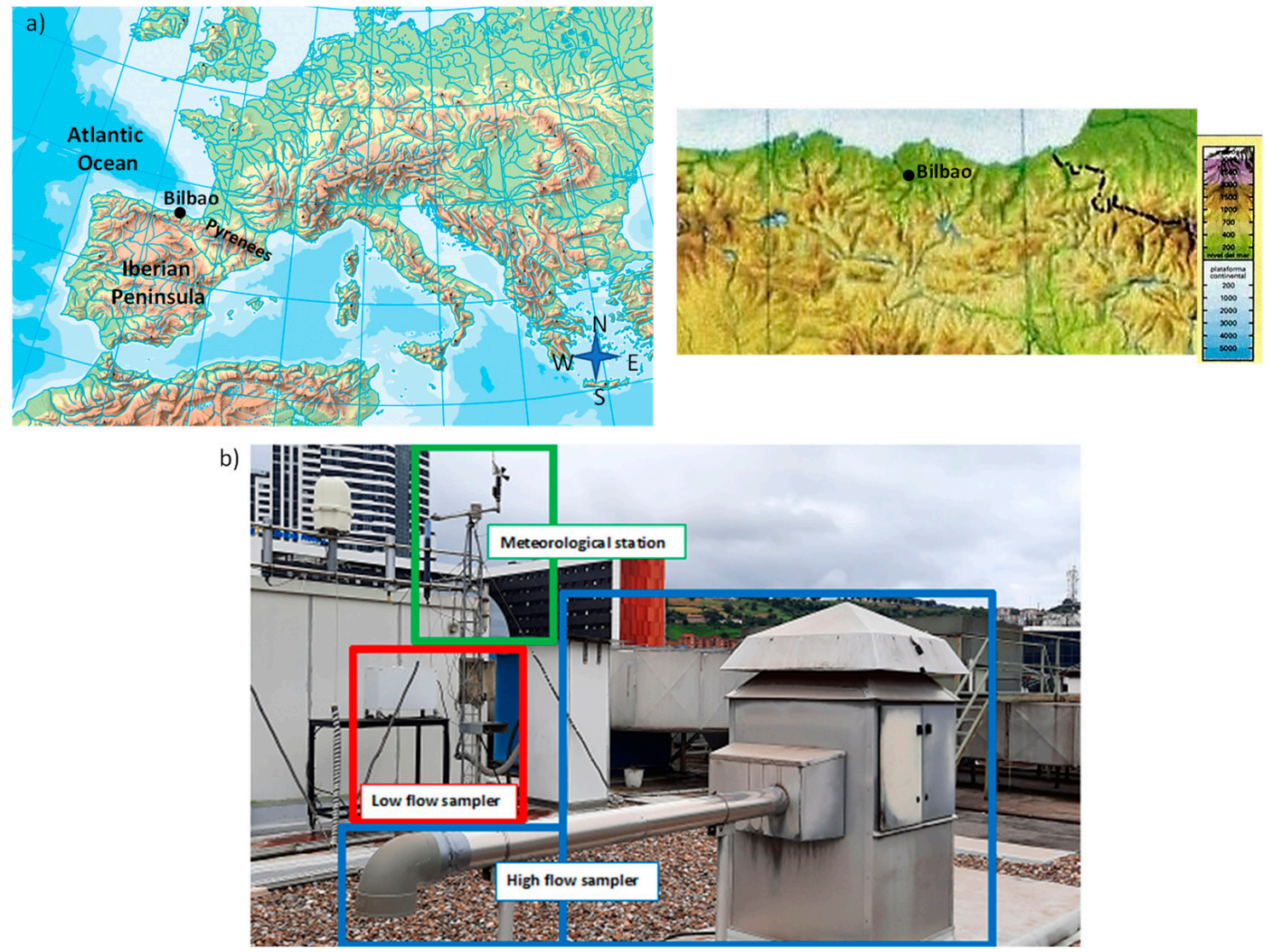

Figure 1. (a) Location of the sampling site in the northern area of the Iberian Peninsula and (b) the aerosol samplers (low and high flow samplers) and the meteorological station used in the present analysis.
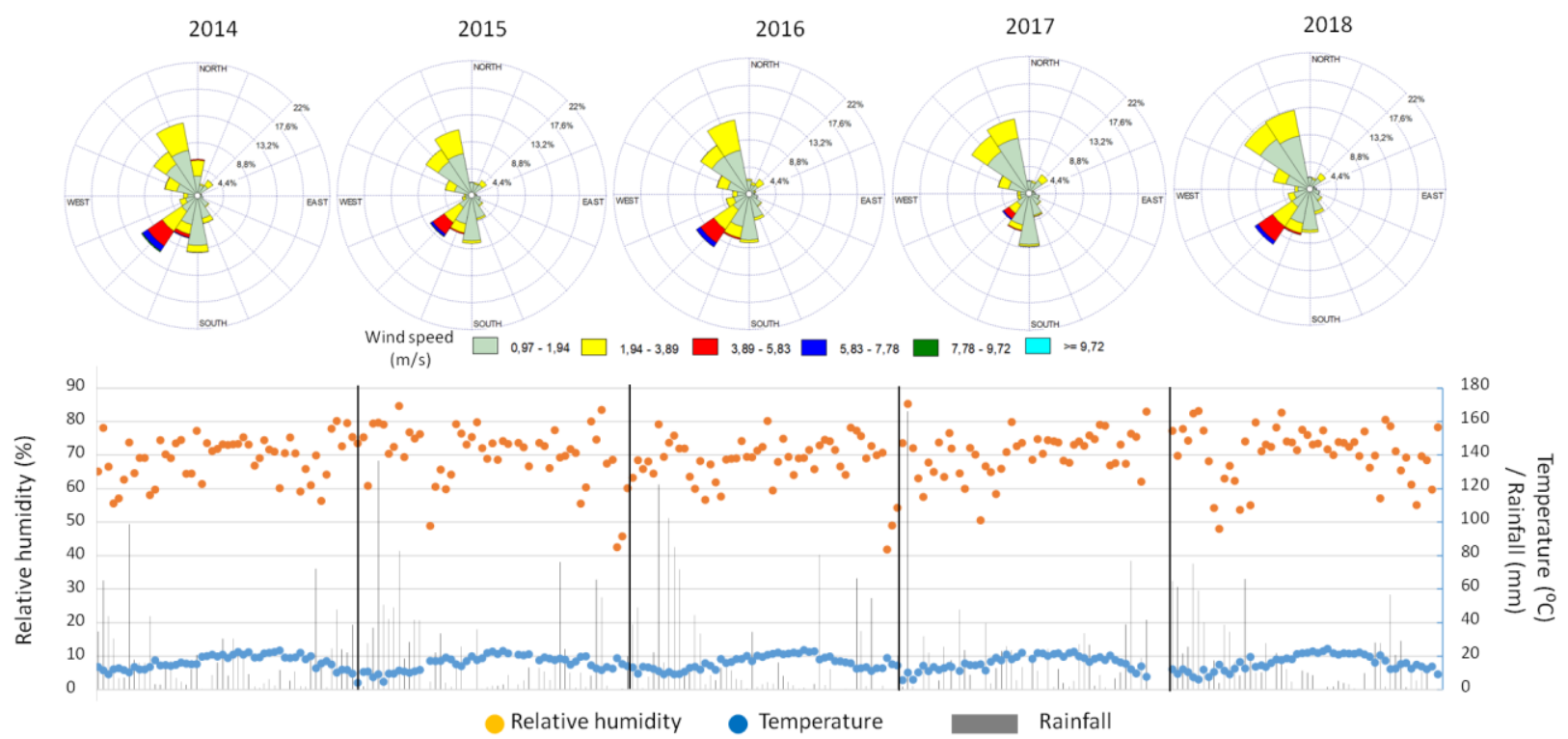

Figure 2. Meteorological measurements during the period 2014-2018 in Bilbao.

\subsection{Beta Activity Concentrations}

Aerosol samples were collected using an air sampler RADECO trademark, mod. AVS28A (17 West Pkwy Plainfield, CT 06374, USA) (Figure 1) that can be considered as a low volume sampler because its nominal flow rate is $30 \mathrm{~L} / \mathrm{min}$. The total volume that can be circulated over the course of a week is about $300 \mathrm{~m}^{3}$, and aerosol sampling takes seven days. 
The filters used in this sampler are cellulose nitrate membrane filters (diameter $47 \mathrm{~mm}$ and 0.8 um pore size). Every week, the filter was removed from the sampler and was placed in a dryer in our laboratory. The filter was kept in its location outside for six days each week before measurements were taken in order to allow the thoron and radon short-lived alpha progeny to decay, and, after that, the samples were measured in a gas flow proportional counter. In order to determine the dust content in the filter, before and after the sampling periods, they were weighted.

A proportional counter with 10 detectors, a Berthold LB 770 10-Channel $\alpha-\beta$ LowLevel Counter, was used for the measurements. The system was calibrated by counting standard samples that had been prepared with the same geometry, in this case, with a ${ }^{90} \mathrm{Sr} /{ }^{90} \mathrm{Y}$ standard source. The efficiency of the detectors was between $39 \%$ and $42 \%$, which was obtained with a measurement of at least 20,000 counts. The background of the detector using a clean filter was determined by four cycles of $1000 \mathrm{~min}$, which were measured on the weekend before the measurements were taken. The counting time was $1000 \mathrm{~min}$, and the detection limits obtained were between $9.45 \mu \mathrm{Bq} / \mathrm{m}^{3}$ and $129.30 \mu \mathrm{Bq} / \mathrm{m}^{3}$, and the uncertainties, which had a coverage factor $\mathrm{k}=2$, were $13.50 \pm 10.05 \mu \mathrm{Bq} / \mathrm{m}^{3}$. In the same filters, the alpha and beta activity concentration could be sampled and measured, so the values could be used for a previous alpha concentration study that was taking place during the same period [16]. On the same roof where the low air sampler was located, there was also a high flow sampler. From 2001 to 2018, during two periods of time (2001-2008 and 2009-2018), the ${ }^{7}$ Be concentration had been analysed $[14,15,17,18]$.

The following checks were performed to rule out a sampling problem and/or any problems with the measurement equipment. We checked the sampler, and the flowmeter records were studied by combining the results with the weight of the dry waste. The analysis revealed normal values. Calibration of the sampler and the maintenance were also correct. A daily control time of $4 \mathrm{~min}$ and a weekly equipment background of $4000 \mathrm{~min}$ were performed, and normal values were obtained. Every 3 years, calibrations were performed, and in the studied periods, three calibrations were completed, obtaining good results of the equipment, as expected.

\subsection{Meteorological Parameters and Backward Trajectories}

In this study, we considered the hourly values of temperature, relative humidity, precipitation, and wind speed and direction measured on the roof of the Faculty of Engineering of Bilbao. We used the WRPLOT View software [19] to generate wind rose diagrams. In addition, the set of backward air trajectories was calculated using the HYSPLIT (Hybrid Single-Particle Lagrangian Integrated Trajectory) model [20,21], taking meteorological inputs from the Global Data Assimilation System (GDAS) with a temporal resolution of $6 \mathrm{~h}$ and a spatial resolution of $1^{\circ}$. These files include vertical wind component information, which makes it possible to calculate three-dimensional kinematic air trajectories. Following the methodology used in previous studies conducted in the same area [17], air trajectories with a duration of $96 \mathrm{~h}$, in time steps of $1 \mathrm{~h}$, and at an ending altitude of $100 \mathrm{~m}$ above ground level were calculated. Four backward air trajectories were calculated for each sampling period considered in the present study (one every six hours). An amount of 7224 backward air trajectories was calculated. The cluster technique implemented in the HYSPLIT model [22] was used to identify airflow patterns, and synoptic scenarios. This technique has worked very well in previous studies [23], and more information can be found in the HYSPLIT model user guide.

\section{Results and Discussion}

\subsection{Beta Activity Concentrations}

Figure 3 presents time behaviour of weekly beta activity concentrations along the five studied years (from 2014 to 2018) in Bilbao. Beta activity concentrations in the aerosol samples range from $1778 \mu \mathrm{Bq} / \mathrm{m}^{3}$ to $35.45 \mu \mathrm{Bq} / \mathrm{m}^{3}$, with an average over the five years of $520.12 \pm 281.77 \mu \mathrm{Bq} / \mathrm{m}^{3}$, where the uncertainty is given as the sample standard deviation. 
These levels are consistent with those reported in other studies conducted in the different areas of Spain, such as in the south $[9,24,25]$, in the east [8], and in the west [11].

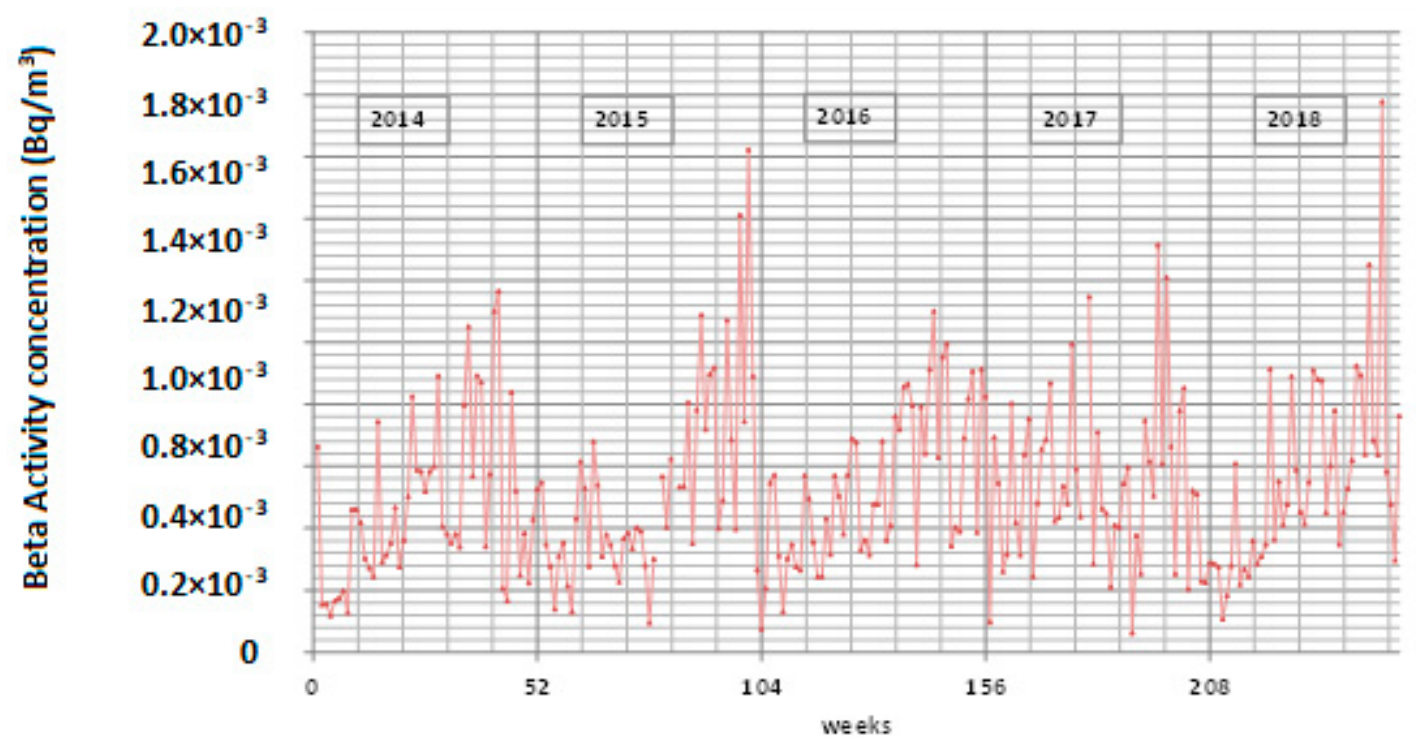

Figure 3. Temporal distribution of weekly beta activity concentrations over the period 2014-2018 in Bilbao.

These set of data can be considered to be a time series after applying the total and partial correlation. A time series can be decomposed into four components: trend, seasonality, cyclical component, and irregular component. Trend represents the evolution of the series over a long period of time and needs yearly values. As such, in this case, the analysis of trend is not relevant because only 5 years cannot explain future evolution. In Figure 4, the trend of the series is shown.

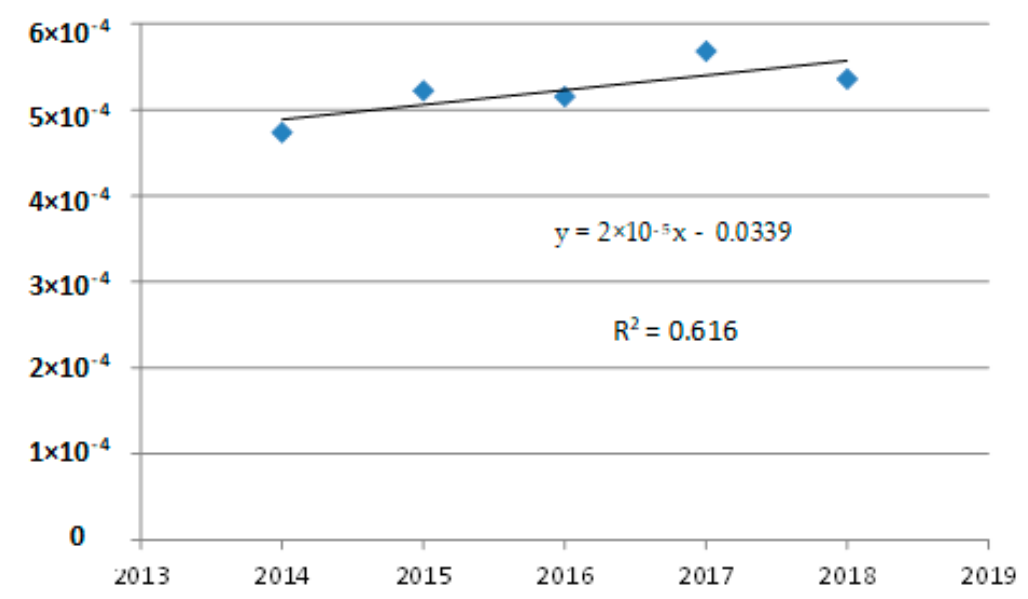

Figure 4. Trend for the period 2014-2018 in Bilbao.

For annual (non-seasonal data) data, more data are better, but sometimes, 25 observations can give an acceptable accuracy [26]. However, the seasonality and the cyclical component, due to the fact that the analysed periods of time are lower than a year, can be studied, and the autocorrelation total and partial are the tools for this study. For the autocorrelations, the delay is indicated on the $X$-axis, and the correlation value is indicated on the $Y$-axis (between -1 and 1 ). Both correlations show a certain correlation between the observed values (represented in blue)with a time delay of $k=52$ weeks, which allows us to affirm the presence of a seasonal component in the time series (Figure 5). 

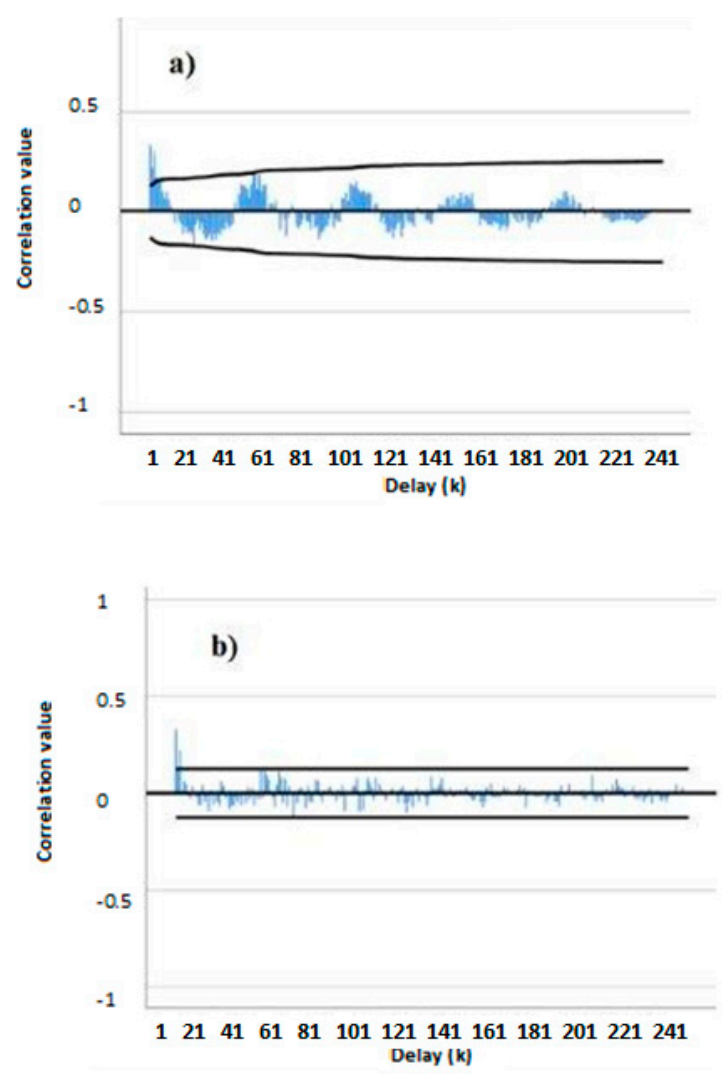

Figure 5. (a) Total autocorrelation and (b) partial autocorrelation of weekly beta activity concentrations over the period 2014-2018 in Bilbao. The correlation lines are represented in black and the correlation values for the delays are in blue.

The existence of this dominant seasonal and cyclical behaviour in Bilbao is statistically justified by the periodogram calculated and shown in Figure 6 . The $X$-axis represents frequency, and the $Y$-axis represents the spectrum. While the first peak represents a one-year period beta activity concentration activity (frequency $1.93 \times 10^{-2}$ week $^{-1}$, i.e., 52 weeks), the second peak (frequencies $3.9 \times 10^{-2}$ week $^{-1}$, i.e., 25 weeks) is the one representing the intra-annual variability. In addition, the Grubbs test was used to study the existence of outliers among the registered values and concluded that there were no outliers in the present set of data because G-crit > G-crit with a $99 \%$ confidence interval on the $p$-value.

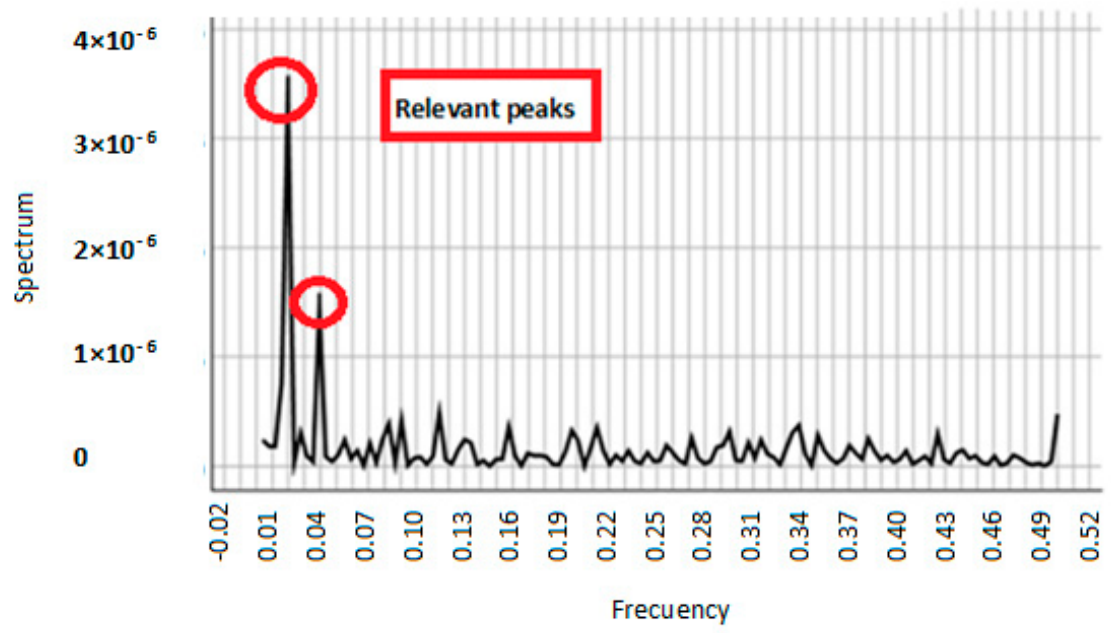

Figure 6. Periodogram of weekly beta activity concentrations over the period 2014-2018 in Bilbao. 
These results agree with the components of the alpha activity concentration identified and analyzed in previous studies at the same site [16]. In this sense, a positive correlation between alpha and gross beta (0.67) was found, which can be explained by the principal source term of both the airborne alpha and gross beta concentration being the same in normal situations. In addition, the alpha/beta ratio was calculated for each week. The average was 0.138 , which is close to the normal ratio of 0.1 [3] as well as to other values obtained in Spain (0.14 in Salamanca (west) [11]; 0.1 in Malaga (south) [9]; 0.2 in the Canary Islands (south) [13]; and close to 0.1 in Valencia (east) [8]). Nevertheless, despite the fact that the ${ }^{7}$ Be values show seasonality and annual periodicity, the correlation with the beta activity values is negligible, with acorrelation value of 0.16 , which is similar to the value obtained in the Canary Islands (0.16) [13].

Every year, maximum values are reached during autumn (October-NovemberDecember), while the minimum ones are registered during winter (January-FebruaryMarch) (Figure 7). Box-plots describing the shape of the seasonal distribution of values and its variability help to summarize and compare this seasonal variability of the beta activity concentrations. A positive trend during the year is shown, with all of the calculated percentiles (i.e., the percentage of values that fall below the xth percentile) increasing from winter to autumn in the same year. The minimum value (P5) increases from $107 \mu \mathrm{Bq} / \mathrm{m}^{3}$ to $224 \mu \mathrm{Bq} / \mathrm{m}^{3}$, while the maximum value (P95) ranges from $803 \mu \mathrm{Bq} / \mathrm{m}^{3}$ to $1315 \mu \mathrm{Bq} / \mathrm{m}^{3}$. The occurrence of the maximum in autumn is not in line with previous works analyzing beta activity concentrations conducted in the Iberian Peninsula [16-18], which showed that the maximum average values are reached in the summer and that the minimum values are obtained in the winter. On the contrary, similar behaviour has been found in other analyses, such as in Milan [27] and New York [28]. This seasonal variation in the beta activity concentrations points to the potential effect of atmospheric factors on these activities in order to justify the heterogeneity of concentrations in different periods of the year, which will be investigated in the next two sections.

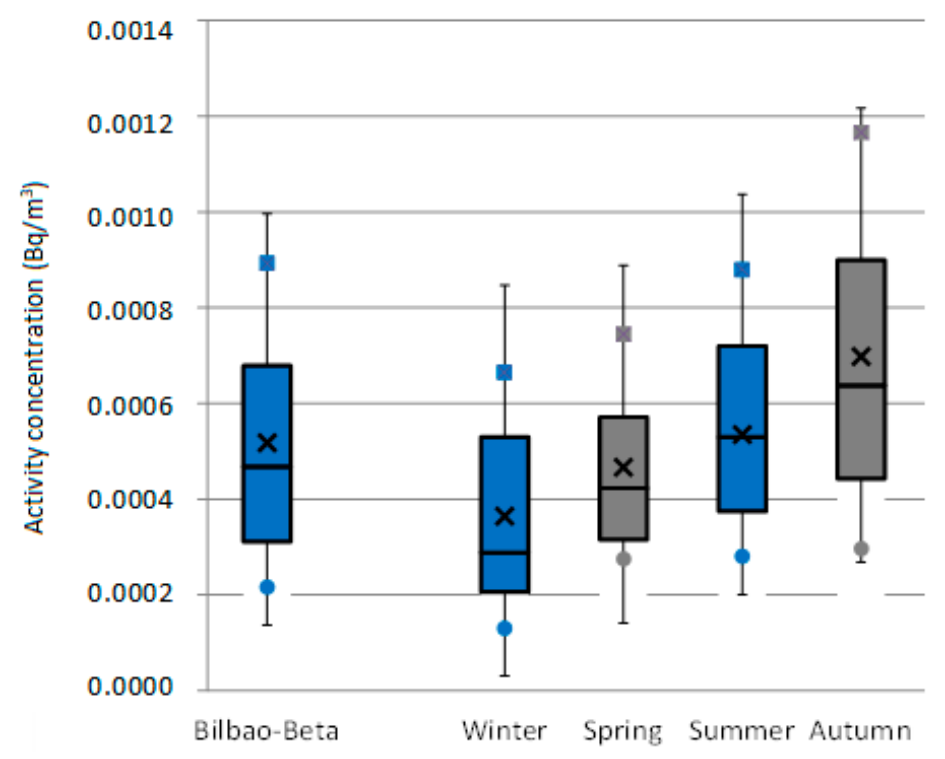

Figure 7. Total and seasonal box-whisker plots for beta activity concentrations over the period 2014-2018 in Bilbao. The rectangle represents the 50\% of data (interquartile range from 25th (P25) to 75th (P75) percentile), the small cross identifies the mean, the continuous horizontal line inside the rectangle identifies the median (50th percentile, P50), the squares and circles identify the 90th (P90) and 10th (P10) percentiles, respectively, and the whiskers extend between the 95th (P95) and 5th (P5) percentiles. 


\subsection{Meteorological Impact of Beta Activity Concentrations}

In the present analysis, we have taken the following months to define corresponding seasons: winter (January, February, and March), spring (April, May, and June), summer (July, August, and September), and autumn (October, November, and December). Time series of temperature, relative humidity, precipitation, wind speed and direction were used to study the influence of the atmospheric factors on the airborne beta activity in Bilbao (Figure 2). Averages of each atmospheric factor corresponding to each sampling period were calculated, except for precipitation, which was calculated as the weekly sum.

Correlations between beta activity concentrations and these atmospheric factors were calculated to evaluate the linear relations between them. Figure 7 displays the scatter plot obtained and the Pearson Correlation (PCC) (in Figure 5, PCC appears as r) performed at the significance level of 0.05 for the beta concentrations, and each of the meteorological parameters that were considered. The distribution of the corresponding pairs of values is indicated by different colors based on the P90, P75, P50, P25, and P10 percentiles (Figure 8). The correlations found were around zero, i.e., there is no relationship between the two variables displayed. The highest one is the positive correlation between the beta and temperature (PCC $=0.20$ ), which is associated with the thermal differences and cyclical behavior of temperature over the years, with minimum temperatures in the winter and maximum temperatures in the summer. There is a negative correlation with relative humidity $(\mathrm{PCC}=-0.04)$ and precipitation $(\mathrm{PCC}=-0.02)$, which would indicate an influence on the decrease in the activity because of the scavenging of airborne radionuclides by rainfall and high relative humidity conditions.

This figure also displays the set of wind rose diagrams associated with each range of beta activity concentrations. This tool provides a complete and practical summary of the correlations between prevailing wind speeds and directions and beta activity concentrations in Bilbao. Wind direction is grouped in sixteen sectors, while wind speed is grouped on six 6-velocity-range discretization. To read each wind rose, each angular histogram of the wind direction only contains the information on the relative frequency of the wind blowing from this certain direction sector, and each color represents the wind speed relative frequencies for each given direction sector.

As it can be seen, the wind in the present study area is blows predominantly from the northwest-north and south-southeast directions, which is in agreement with Figure 8. There is a negative correlation ( $\mathrm{PCC}=-0.12$ ) between the wind speed (weekly average) and beta activity concentrations, which suggests that low (high) wind speeds would favour higher (lower) concentrations of beta activity concentrations. This fact is confirmed by analysing the wind roses obtained for different beta activity concentrations. Minimum beta activity concentrations $(<\mathrm{P} 10)$ are characterized by slightly higher wind speeds in all directions, while the maximum concentrations are clearly associated with low wind speeds. This fact agrees with what was expected, i.e., the dispersion rates of substances in the atmosphere are governed by the strength of the wind, causing a remarkable dispersion and dilution during windy periods and an accumulation during less windy periods. In addition to differences in wind speed, a decrease in the occurrence of winds blowing from the northwest (from the sea) can be observed when comparing the wind roses of the maximum (P90) and minimum beta activity concentrations (P10). It can be concluded from Figure 8 that the highest beta activity concentrations in Bilbao are characterized by low wind speeds that mainly blow in the southeast direction (from land) as well as by low relative humidity and high temperature. 

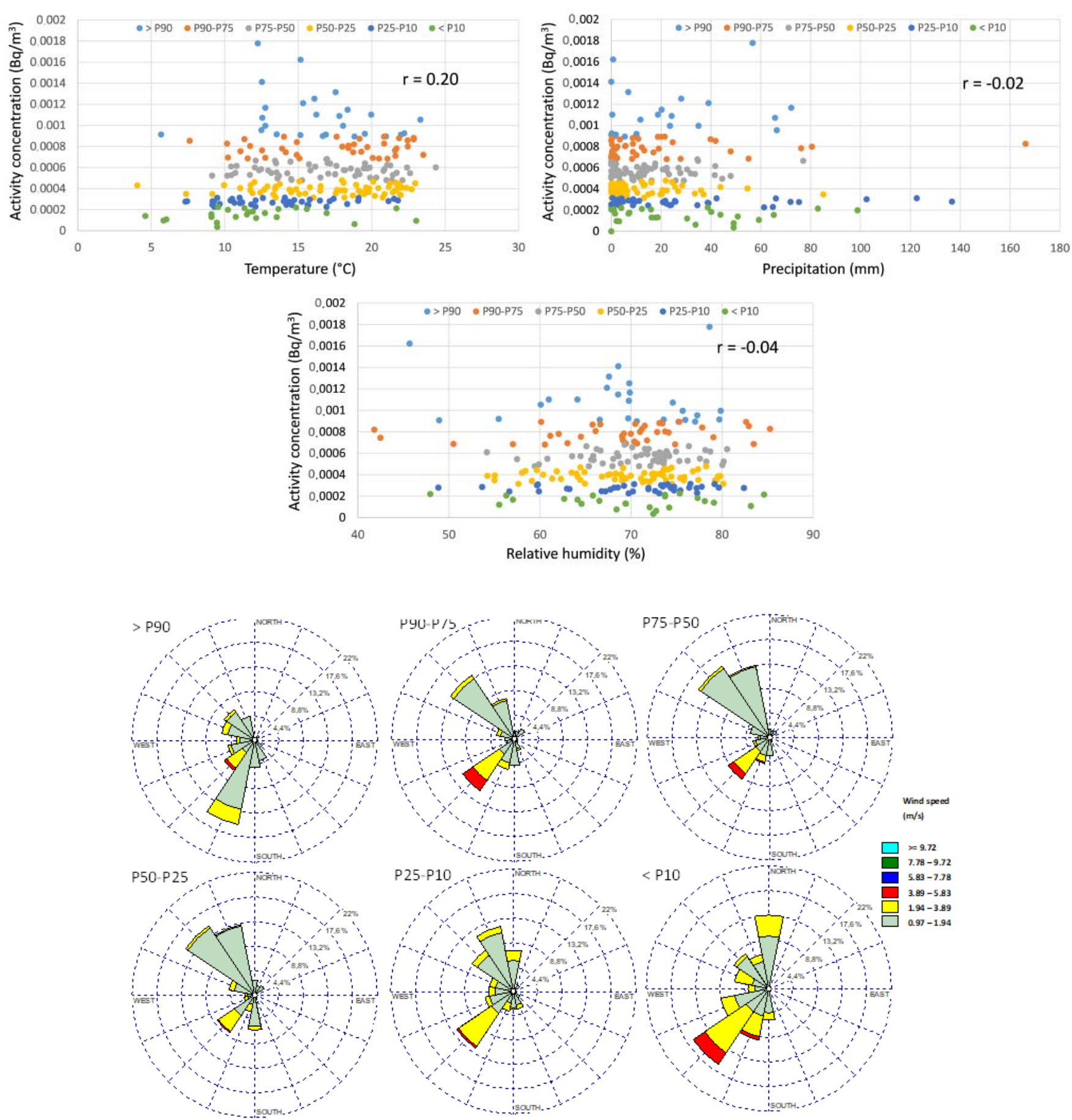

Figure 8. Relationship between temperature, precipitation, relative humidity, wind speed and direction, and beta activity concentrations in Bilbao.

\subsection{Case Studies}

Figure 9 shows the year-to-year variability of the beta activity concentrations measured in the city of Bilbao from 2014 to 2018. This graphical method of displaying variation in a set of data is often used in exploratory data analysis for a first glance at the data [29]. Figure 8 shows that the mean is always greater than the median (P50), which denotes a dominance of low beta activity concentrations as well as the large impact of occasional high values. The variability in these high values can also be observed by considering the positive asymmetrical distribution from 2014 to 2017 (P75 value is farther from the median 
than P25). In 2018, however, this does not happen, and more variability in the low beta activity concentrations is observed. In line with this, we note an increasing trend in the annual mean values (squares) from 2014 to 2017 (beta activity concentrations increased $16 \%$ ), which is broken in 2018.

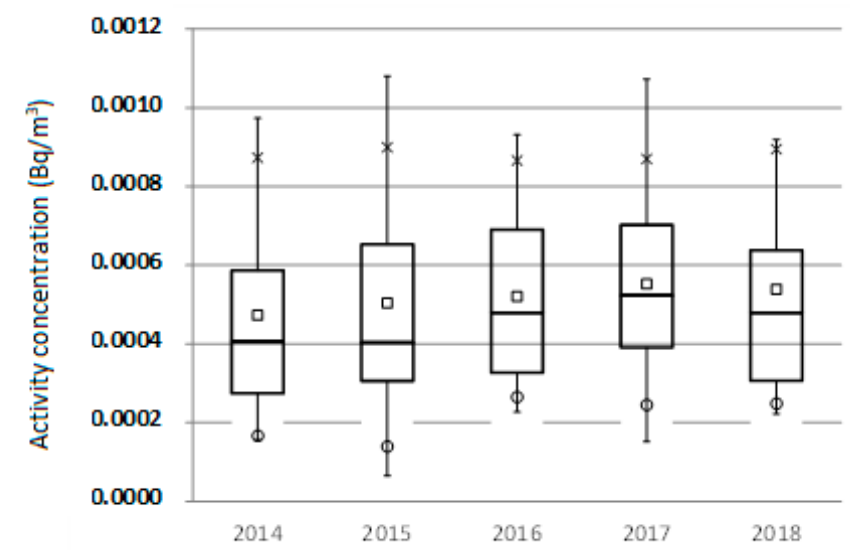

(a)

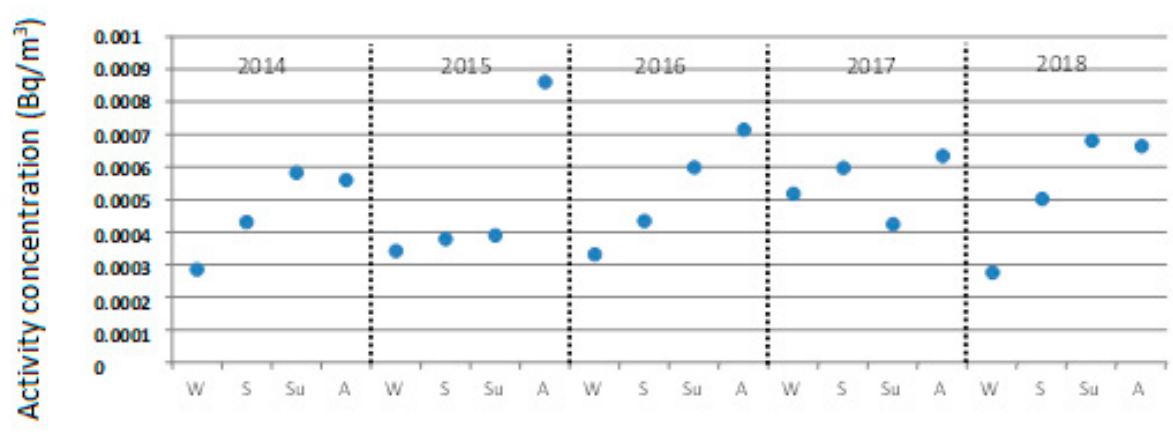

(b)

Figure 9. (a) Year-to-year variability and (b) seasonal average in the city of Bilbao over five years (2014-2018) for beta activity concentrations. W: winter; S: spring; Su: Summer, A: autumn.

To complement and understand this year-to-year variability, Figure 8 also displays the seasonal average of the beta activity concentrations during this five-year period by considering the monthly distribution that was indicated previously. There is a clear behavior to reach the lowest concentrations in winter, while the maximum concentrations are registered in the summer (2014-2018) or in the autumn (2015, 2016, 2017). In this figure, however, there are some anomalous "seasons" that clearly influence the annual beta activity concentrations, such as in 2017, in which the seasonal winter values are largely different and higher than in the rest of the years, or in 2015, in which autumn is the highest seasonal value obtained in Bilbao. Therefore, if aiming at understanding the year-to-year variability, the meteorological conditions associated with these anomalous seasons should be analysed in order to understand the origin and the reasons for these beta activity concentrations in Bilbao. Considering the weak correlation of beta activity concentrations with temperature, relative humidity, and rainfall obtained in Section 3.2, we focused on the analysis of the wind conditions. In this sense, this fact cannot exclude the impact that these meteorological factors have on the beta activity concentration variations, as has been investigated in previous studies [30,31]. However, we have focused on investigating the impact that air masses and prevailing surface winds, i.e., from synoptic to local, have on this intraannual variation and how differences during the year and between years can 
cause temporal variations in beta activity concentrations. To this purpose, wind roses and air mass trajectories were used. The use of backward trajectories is justified due to the impact that airflow patterns have over the surface weather conditions and aerosol concentrations in a given area and over a period of time [32]. The set of synoptic scenarios was analysed by clustering the backward trajectories calculated for all sampling periods.

(a) Autumn 2015

Six airflow patterns were identified by considering the set of backward trajectories during autumn in 2014, 2016, 2017, and 2018. Similar clusters from the west (W), northwest $(\mathrm{NW})$, and north $(\mathrm{N})$ were identified as well as one cluster grouping trajectories with slow continental displacement (Figure 10). Similar clusters were found in previous studies conducted in Bilbao [4]. However, large difference in the displacement and frequencies of the airflow patterns are shown when comparing both sets of results. In autumn 2015, there was a decrease in the percentage of air masses from the NW and W (from $45 \%$ to $32 \%$ ) and from the $\mathrm{N}$ (from $25 \%$ to $10 \%$ ). This fact, however, is the opposite in terms of the arrival of NE air masses, with $10 \%$, and in those with the smallest displacement $(\mathrm{Nb})$, from $31 \%$ to $40 \%$. Both present the arrival of continental air masses, which would mean that there is a general increase in the arrival of continental air masses (from $31 \%$ to $50 \%$ ) during autumn 2015. This difference in percentage is not represented in surface winds (wind roses), which show similar behaviour in terms of both speed and direction. In this case, this surface air flow is decoupled from the synoptic situation. In the case of Bilbao, the surface wind direction is conditioned by the orientation of the valley axis where the city is located, and hence, surface winds are channeled through the valley. This result suggests that in this specific season, long-range transport could play an important role in the gross alpha, which is higher than the local wind directions.

\section{(b) Winter 2017}

Figure 11 shows the average displacement of each airflow pattern for each period as well as the frequency (number in brackets) of each one. This figure shows that there are not any large differences in the airflow patterns between winter periods. Five airflow patterns that were identified in both periods were considered and taken as a reference to the origin and the average pathway of each airflow pattern; the clusters correspond to westerly $(\mathrm{W})$, northwesterly (NW), northeasterly (NE), and slow continental southerly flows $(\mathrm{Nb})$. This number and type of clusters agree with previous studies conducted in Bilbao [4]. However, large differences between both sets of airflow patterns are found in the frequency of each pattern within each period. In winter 2017, there is a decrease in the arrival of air masses from the NW and W (from 69\% to 49\%) and an increase in air masses from the NE (from 20\% to $28 \%$ ) and especially in the $\mathrm{Nb}$ (from 11 to $28 \%$ ), which represents the shortest air mass displacement and at the lowest level. This kind of air mass trajectory is usually associated with mesoscale circulations, which limit the occurrence of the dispersion of substances in the atmosphere due to the prevalence of weak flows in surface levels. This fact is seen in the corresponding wind rose of winter 2017, in which a decrease in the intensity of surface winds is clearly observed. While in winter 2017, there was a small occurrence of winds with intensities above $4 \mathrm{~m} / \mathrm{s}$; this frequency is much higher in the other years. Hence, these figures mainly suggest that the development of continental and slow $\mathrm{Nb}$ air masses is linked with high beta activity concentrations in this area during the winter. 

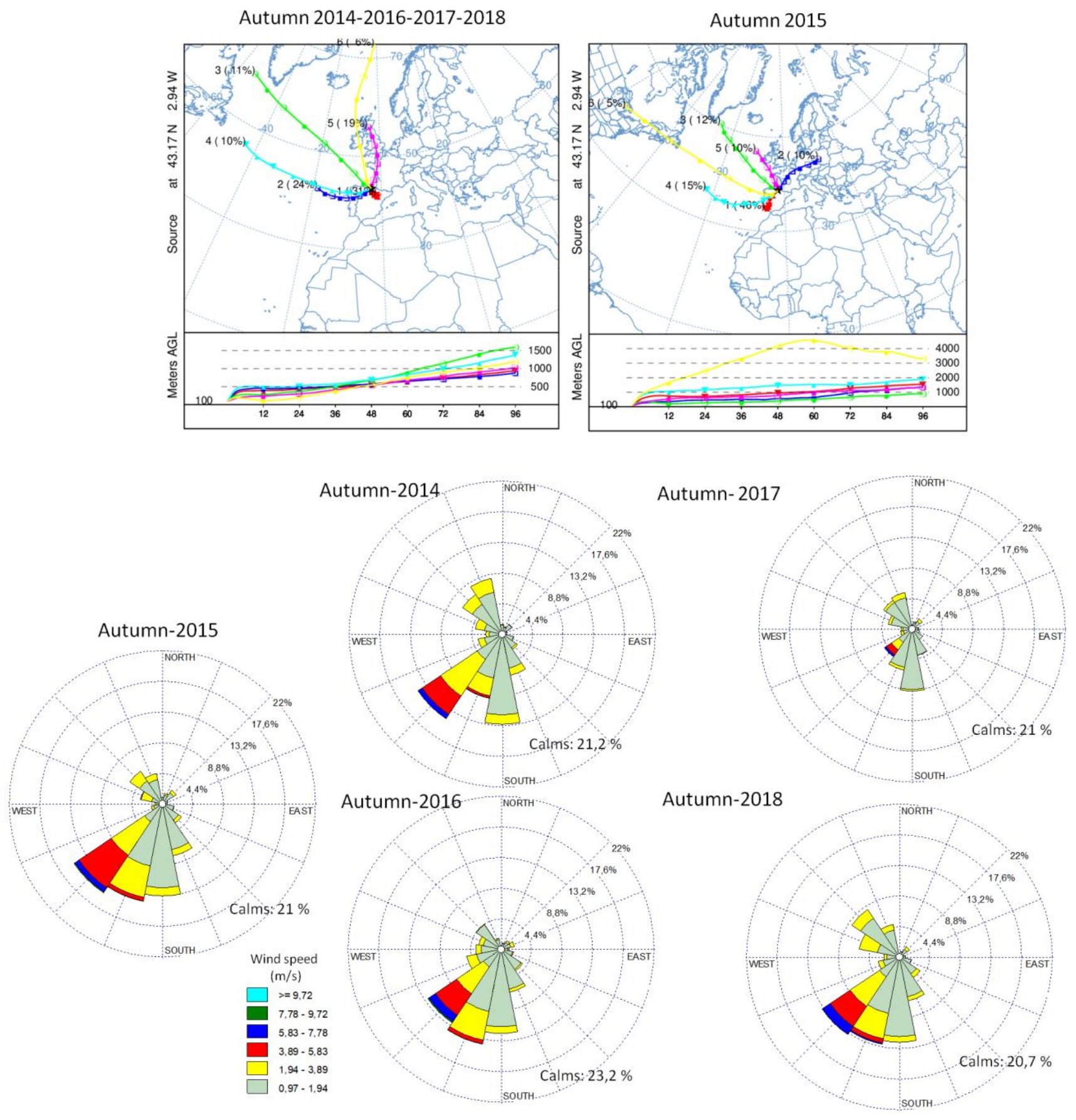

Figure 10. Back-trajectory cluster centers (centroids) obtained at $100 \mathrm{~m}$ agl obtained for airflow pattern for each period and wind roses showing the distribution of surface winds (direction and speed) in percentages for each period considered in Bilbao. The left numbers in the centroids are an identification number of the centroid, and the right numbers (in brackets) are the percentages of the complete trajectories occurring in that cluster. 

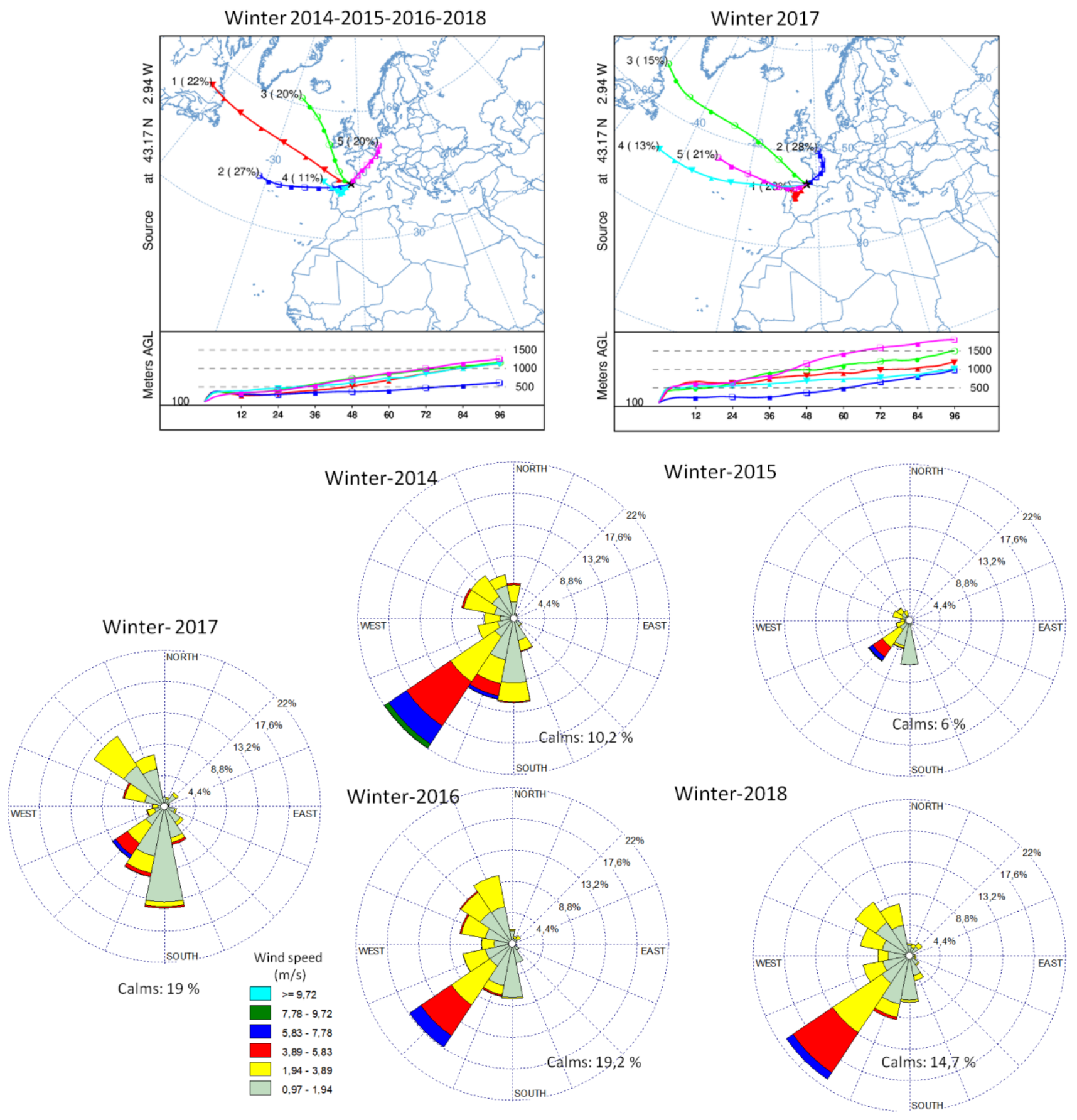

Figure 11. Back-trajectory cluster centers (centroids) obtained at $100 \mathrm{~m}$ agl obtained for airflow pattern for each period and wind roses showing the distribution of surface winds (direction and speed) in percentages for each period considered in Bilbao. The left numbers in the centroids are an identification number for the centroids, and the right numbers (in brackets) are the percentages of complete trajectories occurring in that cluster.

\section{Conclusions}

Beta activity concentration is usually used as a control indicator for radioactivity levels. In the present study, weekly beta activity concentrations from 2014 to 2018 in Bilbao, northern Spain, were analysed (259 data). The autocorrelation function confirmed that these beta activity concentration data can be considered as a time series, and the periodogram showed an annual periodicity and significant seasonal variation of the beta activity concentrations. 
The correlation with the alpha activity concentration (0.138) is similar to other sites in Spain (Salamanca, Málaga, Canary Islands, and Valencia) and are in accordance with United Nations Scientific Committee on the Effects of Atomic Radiation (UNSCEAR) values (0.1). However, there is no correlation (0.16) with the ${ }^{7}$ Be activity concentration measured in the same place, and the results are similar the results found in the Canary Islands. In the current study, no good correlations were found between the meteorological variables (temperature, precipitation and relative humidity). The analysis of the wind behavior under different gross beta activities concluded that the highest beta activity concentrations in Bilbao are characterized by low wind speeds with a mainly southeast wind direction (from land), low relative humidity, and high temperature. The air mass analysis of two anomalous seasonal periods (autumn 2015 and winter 2017) reported the impact of meteorological scenarios on the gross beta activity concentrations and how seasonal variations on synoptic and local winds influence on the intensity of beta activity concentrations.

Author Contributions: Conceptualization, N.A.; formal analysis, N.A. and M.Á.H.-C.; methodology, N.A.; software, N.A.; writing-original draft, N.A. and M.Á.H.-C.; writing-review and editing, N.A., M.Á.H.-C., M.H., R.I. and F.L. All authors have read and agreed to the published version of the manuscript.

Funding: This research received no external funding.

Institutional Review Board Statement: Not applicable.

Informed Consent Statement: Not applicable.

Acknowledgments: The authors gratefully acknowledge the NOAA Air Resources Laboratory (ARL) for the provision of the HYSPLIT transport and dispersion model and/or the READY website (https:/ / www.ready.noaa.gov, accessed on 24 September 2021) used in this publication.

Conflicts of Interest: The authors declare no conflict of interest.

\section{References}

1. Papastefanou, C. Radioactive aerosols. Radioact. Environ. 2008, 12, 11-58.

2. Huang, Y.-J.; Tao, Y.-L.; Lin, J.; Shang-Guan, Z.-H. Annual cycle of gross $\beta$ activities in aerosol around Daya Bay area, China. Chemosphere 2009, 75, 929-933. [CrossRef] [PubMed]

3. United Nations Scientific Committee on the Effects of Atomic Radiation (UNSCEAR). Report 2000: Sources and Effects of Ionizing Radiation; UNSCEAR: New York, NY, USA, 2000.

4. Beer, J.; McCracken, K.; von Steiger, R. Cosmogenic Radionuclides; Springer: Berlin/Heidelberg, Germany, 2012. [CrossRef]

5. IAEA. Radioactive Particles in the Environment: Sources, Particle Characterization and Analytical Techniques; IAEA-TECDOC No. 1663; IAEA: Vienna, Austria, 2011; ISBN 978-92-0-119010-9. ISSN 1011-4289.

6. Mathieu, A.; Kajino, M.; Korsakissok, I.; Périllat, R.; Quélo, D.; Quérel, A.; Saunier, O.; Sekiyama, T.T.; Igarashi, Y.; Didier, D. Fukushima Daiichi-derived radionuclides in the atmosphere, transport and deposition in Japan: A review. Appl. Geochem. 2018, 91, 122-139. [CrossRef]

7. Pham, M.; Chamizo, E.; Lopéz-Lora, M.; Martín, J.; Osvath, I.; Povinec, P. Impact of Saharan dust events on radionuclides in the atmosphere, seawater, and sediments of the northwest Mediterranean Sea. J. Environ. Radioact. 2020, 214-215, 106157. [CrossRef] [PubMed]

8. Sáez-Muñoz, M.; Bas, M.D.C.; Ortiz, J.; Martorell, S. Analysis of the evolution of gross alpha and gross beta activities in airborne samples in Valencia (Spain). J. Environ. Radioact. 2018, 183, 94-101. [CrossRef] [PubMed]

9. Dueñas, C.; Fernández, M.; Liger, E.; Carretero, J. Gross alpha, gross beta activities and 7Be concentrations in surface air: Analysis of their variations and prediction model. Atmos. Environ. 1999, 33, 3705-3715. [CrossRef]

10. Cabello, M.; Dueñas, C.; Liger, E.; Gordo, E.; Cañete, S. Variables influencing the gross alpha and gross beta activities in airborne particulate samples in Málaga, Spain. J. Radioanal. Nucl. Chem. 2018, 315, 299-307. [CrossRef]

11. García-Talavera, M.; Quintana, B.; García-Díez, E.; Fernández, F. Studies on radioactivity in aerosols as a function of meteorological variables in Salamanca (Spain). Atmos. Environ. 2001, 35, 221-229. [CrossRef]

12. Ceballos, M.R.; Borràs, A.; Gomila, E.; Estela, J.M.; Cerdà, V.; Ferrer, L. Monitoring of 7Be and gross beta in particulate matter of surface air from Mallorca Island, Spain. Chemosphere 2016, 152, 481-489. [CrossRef] [PubMed]

13. Hernández, F.; Hernández-Armas, J.; Catalán, A.; Fernández-Aldecoa, J.; Karlsson, L. Gross alpha, gross beta activities and gamma emitting radionuclides composition of airborne particulate samples in an oceanic island. Atmos. Environ. 2005, 39, 4057-4066. [CrossRef]

14. Available online: https://www.enterat.com/_documentos/mapa-fisico-europa-mudo.pdf (accessed on 24 September 2021). 
15. Available online: http://geografos.ftp.catedu.es /index.php\%3Foption=com_content\&view=article\&id=233:bilbao-plano-y-ametropolitana\&catid=72:material-de-aula\&Itemid=92.html (accessed on 24 September 2021).

16. Hernández-Ceballos, M.Á.; Legarda, F.; Alegría, A.N. Analysis of Alpha Activity Levels and Dependence on Meteorological Factors over a Complex Terrain in Northern Iberian Peninsula (2014-2018). Int. J. Environ. Res. Public Health 2020, $17,7967$. [CrossRef]

17. Alegría, N.; Hernández-Ceballos, M.; Herranz, M.; Idoeta, R.; Legarda, F. Meteorological Factors Controlling ${ }^{7}$ Be Activity Concentrations in the Atmospheric Surface Layer in Northern Spain. Atmosphere 2020, 11, 1340. [CrossRef]

18. Alegría, N.; Herranz, M.; Idoeta, R.; Legarda, F. Study of ${ }^{7}$ Be activity concentration in the air of northern Spain. J. Radioanal. Nucl. Chem. 2010, 286, 347-351. [CrossRef]

19. Available online: https://www.weblakes.com/products/wrplot/index.html (accessed on 24 September 2021).

20. Stein, A.F.; Draxler, R.R.; Rolph, G.D.; Stunder, B.J.B.; Cohen, M.; Ngan, F. NOAA's HYSPLIT Atmospheric Transport and Dispersion Modeling System. Bull. Am. Meteorol. Soc. 2015, 96, 2059-2077. [CrossRef]

21. Draxler, R.R.; Stunder, B.; Rolph, G.; Stein, A.; Taylor, A. HYSPLIT4 User's Guide; NOAA Tech. Memo. ERL ARL-230; NOAA Air Resources Laboratory: Silver Spring, MD, USA, 1999. Available online: https:/ /www.arl.noaa.gov/data/web/models/hysplit4 /win95/user_guide.pdf (accessed on 24 September 2021).

22. Stunder, B.J.B. An Assessment of the Quality of Forecast Trajectories. J. Appl. Meteorol. 1996, 35, 1319-1331. [CrossRef]

23. Kelly, G.; Taubman, B.; Perry, B.; Sherman, J.; Soule, P.; Sheridan, P. Aerosol-precipitation interactions in the southern Appalachian Mountains. Atmos. Chem. Phys. 2012, 12, 5487-5517. [CrossRef]

24. Dueñas, C.; Fernández, M.; Carretero, J.; Liger, E.; Cañete, S. Long-term variation of the concentrations of long-lived Rn descendants and cosmogenic ${ }^{7} \mathrm{Be}$ and determination of the MRT of aerosols. Atmos. Environ. 2004, 38, 1291-1301. [CrossRef]

25. Dueñas, C.; Orza, J.; Cabello, M.; Fernández, M.; Cañete, S.; Pérez, M.; Gordo, E. Air mass origin and its influence on radionuclide activities $\left({ }^{7} \mathrm{Be}\right.$ and $\left.{ }^{210} \mathrm{~Pb}\right)$ in aerosol particles at a coastal site in the western Mediterranean. Atmos. Res. 2011, 101, 205-214. [CrossRef]

26. Linden, A. Re: What Should Be the Minimum Number of Observations for a Time Series Model? 2015. Available online: https: / / www.researchgate.net/post/What-should-be-the-minimum-number-of-observations-for-a-time-series-model/ $55004 \mathrm{e} 9 \mathrm{dd} 11 \mathrm{~b} 8 \mathrm{~b} 29418 \mathrm{~b} 463 \mathrm{e} /$ citation/download (accessed on 24 September 2021).

27. Vecchi, R.; Marcazzan, G.; Valli, G. Seasonal variation of ${ }^{210} \mathrm{~Pb}$ activity concentration in outdoor air of Milan (Italy). J. Environ. Radioact. 2005, 82, 251-266. [CrossRef] [PubMed]

28. Gillen, E.A. Airborne activities of gross beta, ${ }^{7} \mathrm{Be}$, and ${ }^{131} \mathrm{I}$ in New York. J. Radioanal. Nucl. Chem. 2005, 264, 387-392. [CrossRef]

29. Solazzo, E.; Bianconi, R.; Vautard, R.; Bessagnet, B.; Chemel, C.; Coll, I.; Ferreira, J.; Forkel, R.; Francis, X.; Grossi, P.; et al. Ensemble modelling and diagnostic model evaluation for surface-level ozone in Europe and North America. Atmos Environ. 2012, 53, 60-74. [CrossRef]

30. Bourcier, L.; Masson, O.; Laj, P.; Pichon, J.; Paulat, P.; Freney, E.; Sellegri, K. Comparative trends and seasonal variation of ${ }^{7}$ Be, ${ }^{210} \mathrm{~Pb}$ and ${ }^{137} \mathrm{Cs}$ at two altitude sites in the central part of France. J. Environ. Radioact. 2011, 102, 294-301. [CrossRef]

31. Tositti, L.; Brattich, E.; Cinelli, G.; Baldacci, D. 12 years of ${ }^{7} \mathrm{Be}$ and ${ }^{210} \mathrm{~Pb}$ in Mt. Cimone, and their correlation with meteorological parameters. Atmos. Environ. 2014, 87, 108-122. [CrossRef]

32. Toledano, C.; Cachorro, V.E.; de Frutos, A.M.; Torres, B.; Berjón, A.; Sorribas, M.; Stone, R.S. Airmass Classification and Analysis of Aerosol Types at El Arenosillo (Spain). J. Appl. Meteorol. Clim. 2009, 48, 962-981. [CrossRef] 